\title{
Dynamics of Spontaneous Emission Controlled by Local Density of States in Photonic Crystals
}

Lodahl, Peter; Nikolaev, Ivan S.; van Driel, A. Floris; Vos, Willem L.

Published in:

Conference on Lasers and Electro-Optics and 2006 Quantum Electronics and Laser Science Conference. CLEO/QELS 2006.

Publication date:

2006

Document Version

Publisher's PDF, also known as Version of record

Link back to DTU Orbit

Citation (APA):

Lodahl, P., Nikolaev, I. S., van Driel, A. F., \& Vos, W. L. (2006). Dynamics of Spontaneous Emission Controlled by Local Density of States in Photonic Crystals. In Conference on Lasers and Electro-Optics and 2006 Quantum Electronics and Laser Science Conference. CLEO/QELS 2006. (pp. 1-2). IEEE.

\section{General rights}

Copyright and moral rights for the publications made accessible in the public portal are retained by the authors and/or other copyright owners and it is a condition of accessing publications that users recognise and abide by the legal requirements associated with these rights.

- Users may download and print one copy of any publication from the public portal for the purpose of private study or research.

- You may not further distribute the material or use it for any profit-making activity or commercial gain

- You may freely distribute the URL identifying the publication in the public portal 


\title{
Dynamics of Spontaneous Emission Controlled by Local Density of States in Photonic Crystals
}

\author{
Peter Lodahl $^{1,2}$, Ivan S. Nikolaev ${ }^{2,3}$, A. Floris van Driel ${ }^{4}$, and Willem L. Vos ${ }^{2,3}$ \\ ${ }^{1} \mathrm{COM} \bullet D T U$ Department of Communications, Optics, and Materials \\ Nano $\bullet D T U$, Technical University of Denmark, DTU - Building 345V, DK-2800 Kgs. Lyngby, Denmark \\ Phone: +45 4525 3807, FAX: +45 4593 6581,E-mail: pel@com.dtu.dk \\ ${ }^{2}$ Complex Photonics Systems, MESA ${ }^{+}$Research Institute, University of Twente, The Netherlands \\ ${ }^{3}$ FOM Institute for Atomic and Molecular Physics (AMOLF), Kruislaan 407 Amsterdam, The Netherlands \\ ${ }^{4}$ Condensed Matter and Interfaces, Debye Institute, Utrecht University, The Netherlands
}

\begin{abstract}
We have measured time-resolved spontaneous emission from quantum dots in 3D photonic crystals. Due to the spatially dependent local density of states, the distribution of decay rates varies strongly with the photonic crystal lattice parameter.
\end{abstract}

C2006 Optical Society of America OCIS codes: (270.0270), (250.5230), (270.5580).

Control over spontaneous emission from excited light sources is of great importance in quantum optics. It is essential for diverse applications such as miniature lasers, light-emitting diodes, and single-photon sources for quantum information. The rate of spontaneous emission depends on the surroundings of the emitter as is quantified through the local density of states that counts the number of available optical modes at a specific position. In a photonic crystal, the local density of states can be strongly modified and thereby used to control spontaneous emission. We demonstrate for the first time [1] that photonic crystals control the spontaneous emission decay rate from quantum dots [2]. We assign our observations unambiguously to the spatial variations of the local density of states [3].


Figure 1. Left: Decay curves of quantum dots in photonic crystals with lattice parameters $460 \mathrm{~nm}$ (1) and $580 \mathrm{~nm}$ (3) compared to measurements on a reference sample with lattice parameter $255 \mathrm{~nm}$ (1). The solid curves are fits to the experimental data using a log-normal distribution of decay rates. Right: Normalized decay distributions for the three different photonic crystals. Clear modifications of both the most-frequent decay rate and the width of the distributions are observed. 


\section{QTuL3.pdf}

We have studied spontaneous emission from CdSe quantum dots embedded in 3D photonic crystals consisting of air spheres in titanium dioxide. In time-resolved experiments, we observe that the spontaneous emission decay curves are strongly dependent on the photonic crystal lattice parameter, c.f. Fig. 1.

The decay curves are successfully modeled using a distribution of decay rates in order to account for different emission rates for individual quantum dots in the ensemble of emitters. The most-frequent decay rate varies by a factor of three when changing the crystal lattice parameter and the distribution width varies by a factor of six. Both broadband inhibition and enhancement is observed, see Fig. 2. The most-frequent decay rate for the photonic samples relative to the measurements on the reference samples is qualitatively described by the total density of states (Fig. 2 (a)) while the pronounced variation of the width of the distribution (Fig. 2(b)) is identified as due to the spatial variation of the local density of states that is probed by quantum dots at different positions.

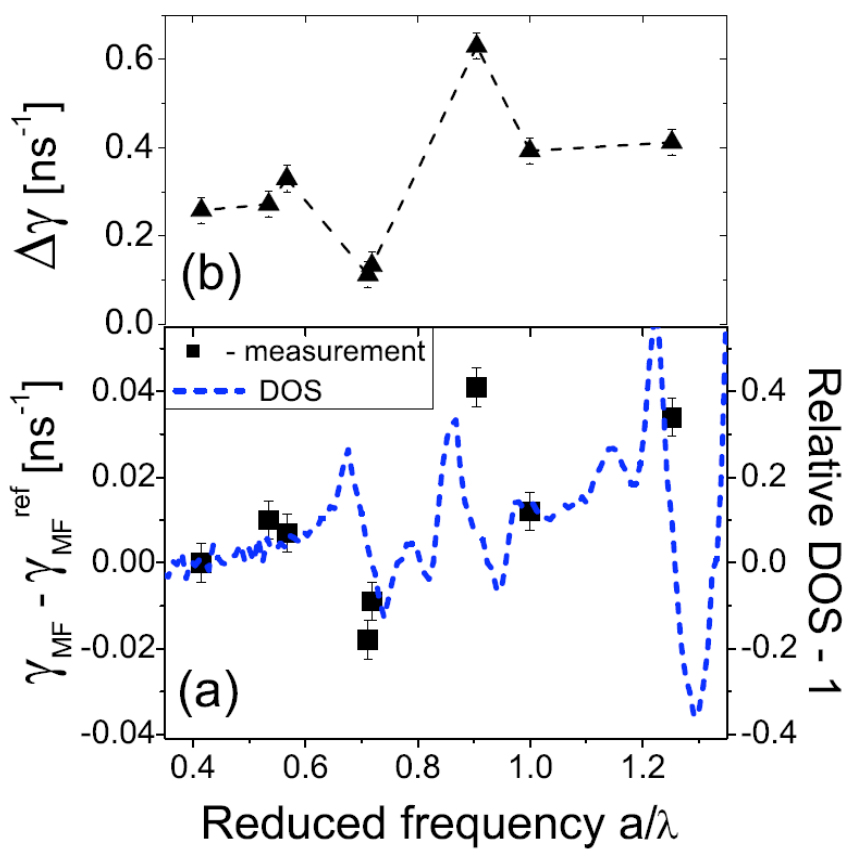

Figure 2. (a) Most-frequent decay rate for the photonic sample relative to a reference sample when varying the lattice parameter a. The experimental data can be modeled with the total density of states (dashed curve. (b) Variation of the width of the decay-rate distribution with lattice parameter.

[1] P. Lodahl, A.F. van Driel, I.S. Nikolaev, A. Irman, K. Overgaag, D. Vanmaekelbergh, and W.L. Vos, "Controlling the dynamics of spontaneous emission from quantum dots by photonic crystals", Nature 430, 654-657 (2004).

[2] A.F. van Driel, G. Allan, C. Delerue, P. Lodahl, W.L. Vos, and D. Vanmaekelbergh, "Frequency-dependent spontaneous emission rate from CdSe and CdTe nanocrystals: influence of dark states”, Phys. Rev. Lett. 95, 236804 (2005).

[3] I.S. Nikolaev, P. Lodahl, A.F. van Driel, and W.L. Vos, "Spontaneous-emission rate distributions in photonic crystals controlled by position-

dependent local density of states", submitted, quant-ph/0511133 (2005). 